Os últimos três anos da revista RECADM foram marcados por muitas mudanças e aprimoramentos. Por essa razão, até para demarcar as consequências de tais mudanças, neste editorial, fizemos registro de alguns números da RECADM desses últimos três anos. Todavia, há informação também que remete a resultados atuais que só foram possíveis devido ao gigantesco empenho dos editores e equipes editorial anteriores, que possibilitaram a RECADM ser o periódico de destaque que é hoje. Nossa intenção é que a comunidade da revista conheça um pouco mais sobre os resultados e processos da revista, estes, por sua vez, fomentarão novos balanços, permitindo que, periodicamente, façamos reflexões sobre os caminhos que estamos seguindo.

Assim, um dos aspectos que eu gostaria de destacar é a trajetória editorial dos últimos três anos. A síntese dessa trajetória é apresentada na Tabela 1, que levanta alguns números acerca do processo da RECADM. Como pode ser visto, publicamos anualmente três edições. Com frequência quadrimestral, mantivemos extrema pontualidade na publicação de cada edição, que deve estar no ar sempre até o primeiro dia do quadrimestre. Com a estabilidade do processo editorial, em termos de suporte tecnológico, foi possível aumentar o número de publicações de 12 artigos por ano (quatro por edição) para 18 artigos por ano (seis por edição), número que não pretendemos aumentar, pelo menos por um bom tempo. Isso porque a política da RECADM é priorizar que bons artigos sejam publicados, e não maior volume.

Tabela 1. Estatísticas de Publicações, Submissões, Avaliações e Audiência da RECADM.

\begin{tabular}{lccc}
\hline \multicolumn{1}{c}{ Ano } & $\mathbf{2 0 1 7}$ & $\mathbf{2 0 1 8}$ & $\mathbf{2 0 1 9 ^ { \mathbf { a } }}$ \\
\hline Edições publicadas & 3 & 3 & 3 \\
Artigos Publicados & 12 & 17 & 18 \\
\hline Total de submissões: & 201 & 222 & 159 \\
Fora do Escopo/Formato & $53(26,4 \%)$ & $60(27 \%)$ & $49(30,8 \%)$ \\
Em avaliação & 0 & $4(1,8 \%)$ & $11(6,9 \%)$ \\
Avaliados pelos pares & $148(73,6 \%)$ & $158(71,2 \%)$ & $99(62,3 \%)$ \\
Aceito & $37(25 \%)$ & $21(13 \%)^{b}$ & $1(1 \%)^{c}$ \\
Rejeitado & $111(75 \%)$ & $137(87 \%)$ & $98(99 \%)$ \\
\hline Tempo médio de avaliação & 92 & 79 & 90 \\
Tempo até a publicação & 284 & 436 & $\mathrm{~N} / \mathrm{D}$ \\
Usuários cadastrados & $4515(587$ novos) & $6441(1926$ novos) & $12877(6436$ novos) \\
\hline
\end{tabular}

a) Dados consolidados até 13 de dezembro de 2019.

b) A aceitação pode chegar a 15,8\%, pois há 4 artigos em avaliação submetidos em 2018.

c) A aceitação pode chegar a 12,1\%, pois há 11 artigos em avaliação submetidos em 2019.

Em termos de submissões, passamos de 201 em 2017 para 222 em 2018, com um declínio para 159 submissões em 2019, até o dia 13 de dezembro deste ano. Há duas razões aparentes para essa queda, porém

Luciano Rossoni (iD,

Editor da RECADM

UniGranRio, Brasil

Irossoni@gmail.com 
puramente especulativas. A primeira pode ser devido ao fato da mudança da forma de avaliação dos programas de pós-graduação pela Capes, que prioriza a produção qualificada ao invés da quantidade de pontos. Tanto que, entre os anos de 2017 e 2018, mesmo com o incremento de novos periódicos, o número total de artigos publicados na área que estão indexados no Spell caiu. Pressupondo que o número de publicações sofre efeito da quantidade de submissões pode-se inferir que provavelmente o número de submissões na área como um todo também caiu, não seria muito diferente com a RECADM. A segunda razão pode ser fruto do maior rigor no processo de avaliação prévia dos manuscritos, que limita as submissões a artigos com somente três autores, bem como tende a fazer uma análise mais rápida e criteriosa no desk review, ao ponto de se ter ouvido que a RECADM é o periódico que "mais reprova artigos no desk reject". Não há como saber se isso é verdade, mas pode ser que a maior seletividade no processo de revisão prévia afaste alguns autores.

O rigor no processo de avaliação também é verificado na trajetória de aprovações e reprovações no decorrer dos últimos três anos. Excluindo os artigos reprovados por formado ou por inadequação de escopo (que saltou de $26,4 \%$ para $30,8 \%$ ), a taxa de aprovação de artigos na RECADM declinou de 25\% em 2017 para 13\% em 2018, podendo chegar, no máximo, a uma taxa de aprovação de 15,8\% nesse ano. Para o ano de 2019, a aprovação máxima será de 12,1\%. Isso não significa que maior taxa de reprovação é uma meta da RECADM. Como limitamos nossas publicações a 18 artigos por ano e com o aumento de projeção da RECADM no cenário editorial da área de administração, a competição entre manuscritos tende a aumentar.

Nosso tempo de avaliação também é bom, girando em torno dos 90 dias, tempo médio bem inferior ao comparado com muitas revistas nacionais. Porém, apesar de sempre buscarmos responder aos autores com a maior celeridade possível, desde que o artigo se inicia nas rodadas de avaliação, tendemos a dar tempo e oportunidade para os autores aprimorarem o artigo. Isso impacta, normalmente, em maior tempo para uma aprovação final, o que, por sua vez, pode atrasar um pouco a publicação definitiva. Tanto que o tempo até a publicação saltou de 284 dias em 2017 para 436 dias em 2018. Mas não somente por isso: como havia um estoque de artigos dos anos anteriores, o tempo de publicação se alongou para atender ao limite de artigos publicados. Para o ano de 2019, ainda não temos informações porque nenhum artigo aprovado em 2019 foi publicado este ano, pois todos comporão as edições de 2020 ou posterior. Então, para os autores que desejam publicar na RECADM, nós avaliamos rapidamente, mas não temos tanta pressa em publicar. Também não fiquem alarmados com o tempo de publicação em 2018, pois o tempo será menor nos anos subsequentes.

Por fim, em relação às estatísticas editoriais, algo impactante para nós foi o aumento expressivo no número de leitores, especialmente no ano de 2019, cuja base quase dobrou, saltando de 6.441 leitores em 2018 para 12.877 leitores em 2019, até o momento. É impossível saber se isso se deve ao maior empenho em divulgar a RECADM nas mídias sociais ou por meio de folders e marcadores de livros, ou ainda devido ao novo layout do site, que ficou mais orgânico. Outra possibilidade pode ser até mesmo o maior 
interesse da comunidade devido à curiosidade em conhecer as mudanças que fizemos nas tecnologias de editoração. Fato é que hoje temos muitos mais leitores para compartilhar diretamente nossos resultados.

Como consequência, o número de acessos e downloads cresceu no decorrer do ano, como pode ser verificado no gráfico seguinte. Desconsiderando os meses de férias escolares, verificamos que o número de downloads saltou de aproximadamente 4.000 no primeiro semestre para mais de 5.000 no segundo semestre. O número de acessos também cresceu, passando de 8.000 em média no primeiro semestre para 9.500 no segundo. A maior limitação desses números é que o mecanismo de contagem de acessos foi implementado em dezembro de 2018, o que não permite a comparação com os anos anteriores. Ademais, não há como saber os acessos em outras fontes na internet sem ser do próprio site da RECADM.

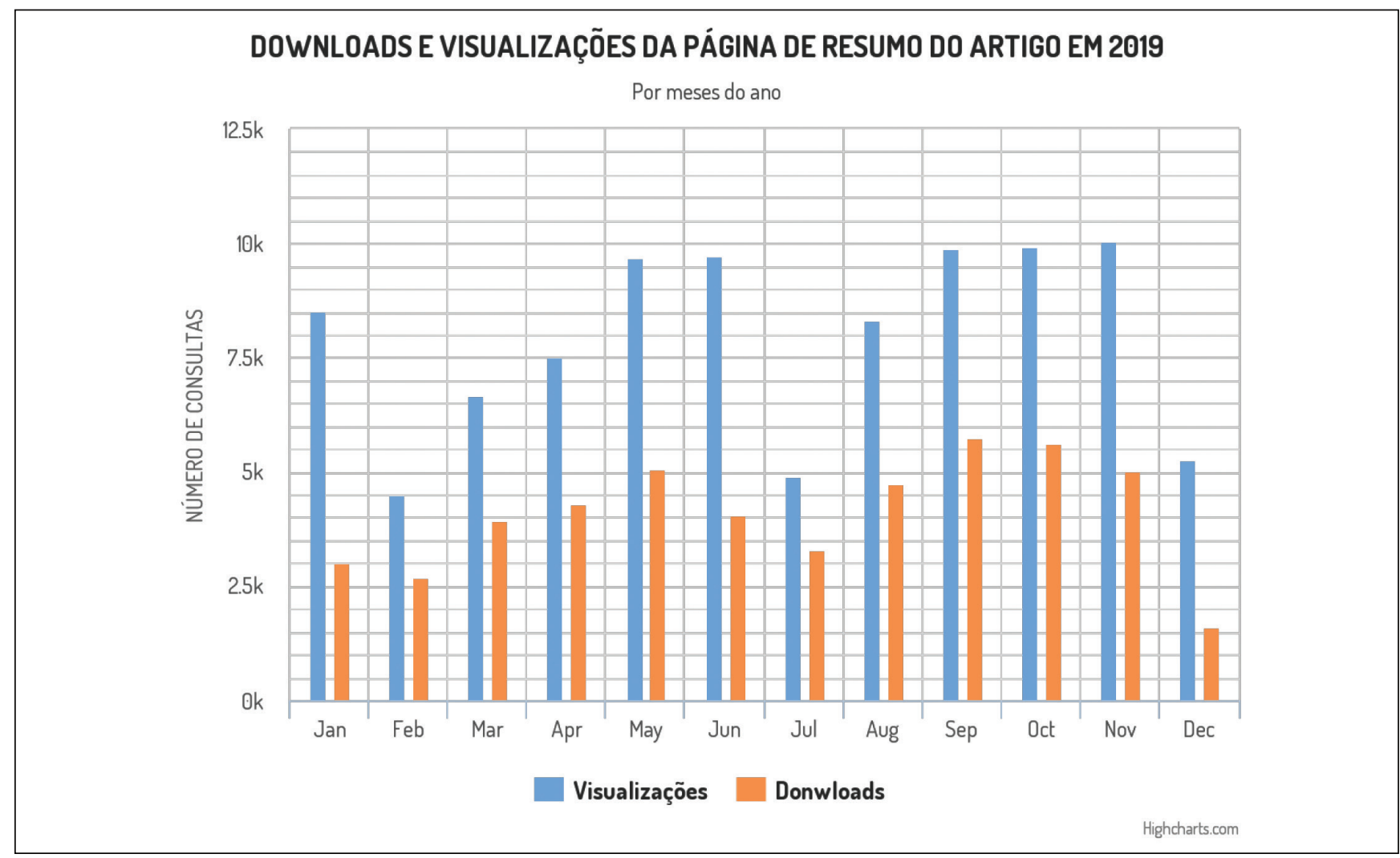

Nota: Gráfico atualizado até 13 de dezembro de 2019.

Fonte: http://www.periodicosibepes.org.br/index.php/recadm/statistics, coletado em 13 de dezembro de 2019.

Deve-se lembrar que, quando um periódico é acessado ou que tenha documentos baixados, quem é visível de fato é o artigo, não o periódico em si. Então eu gostaria de destacar neste balanço os dez artigos mais baixados na RECADM até agora. Deve-se ressaltar, novamente, que essas estatísticas são primordialmente de downloads no ano de 2019, pois a ferramenta de contagem foi implementada no final de 2018. Independentemente disso, pode-se verificar a variabilidade de temas que vêm chamando atenção da 
comunidade acadêmica, reforçando o papel que a RECADM dá a pluralidade de perspectivas. É evidente também que muitos dos artigos mais baixados envolvem temas populares, cujo apelo para trabalhos de conclusão de curso da graduação é grande.

Tabela 2. Artigos mais baixados no portal da RECADM.

\begin{tabular}{|c|c|c|}
\hline Ordem & Artigo & Downloads \\
\hline 1 & $\begin{array}{l}\text { "Precário não é, mas eu acho que é escravo": Análise do Trabalho dos Motoristas da Uber sob o Enfoque da } \\
\text { Precarização }\end{array}$ & 1352 \\
\hline 2 & $\begin{array}{l}\text { Rumo à Economia Circular: Sinergia Existente entre as Definições Conceituais Correlatas e Apropriação para a } \\
\text { Literatura Brasileira }\end{array}$ & 1065 \\
\hline 3 & Motivação e Liderança: Um Trabalho em Equipe nas Organizações & 1021 \\
\hline 4 & Finanças Comportamentais: Análise do Perfil Comportamental do Investidor e do Propenso Investidor & 1002 \\
\hline 5 & A Política de Recompensa e Promoção Influencia a Motivação do Trabalhador? & 908 \\
\hline 6 & Estrutura Organizacional e Gestão do Conhecimento & 868 \\
\hline 7 & Nível de alfabetização financeira dos estudantes universitários: afinal, o que é relevante? & 735 \\
\hline 8 & 0 papel do governo e a prática do consumo sustentável: como esse stakeholder atua no setor elétrico? & 669 \\
\hline 9 & A Qualidade dos Serviços Contábeis como Ferramenta de Gestão para os Escritórios de Contabilidade & 652 \\
\hline 10 & Um estudo sobre a satisfação do consumidor esportivo que frequenta estádios de futebol em Belo Horizonte & 638 \\
\hline
\end{tabular}

Fonte: http://www.periodicosibepes.org.br/index.php/recadm/statistics, coletado em 13 de dezembro de 2019.

Além dos downloads, que podem ser convertidos em leitura, outro conjunto de indicadores que nós gostaríamos de ressaltar neste balanço é o de citações da RECADM no Spell e no Google, o que pode ser visto na Tabela 3. No Spell, temos um total de 291 citações dos 350 documentos, o que dá uma média de 0,8 citações por artigo. Já no Google, uma base muito mais ampla, mas bem menos seletiva que o Spell, houve 1569 citações até o momento, cuja média é de 4,5 citações por documentos. Esses números apontam o quanto a RECADM vem influenciando o meio acadêmico e educacional no país, pois os trabalhos publicados no periódico estão servindo de fonte de referência e de fonte de inspiração para muitos pesquisadores.

Tabela 3. Indicadores de Citação da RECADM.

\begin{tabular}{lcc}
\hline & Spell $^{\mathrm{a}}$ & Google Acadêmico $^{\circ}$ \\
\hline Citações & 291 & 1569 \\
Documentos & 350 & 350 \\
Citações por Documentos & 0,8 & 4,5 \\
Impacto 20182 anos & $0,333(0,292)^{\mathrm{b}}$ & - \\
Impacto 20185 anos & $0,369(0,357)^{\mathrm{b}}$ & - \\
índice H & 6 & 19 \\
índice H5 & - & 14 \\
índice i10 & 4 & 52 \\
\hline
\end{tabular}

Nota: Dados coletados em 16 de dezembro de 2019.

a) Estatísticas de citações geradas a partir de 2010.

b) Valores entre parênteses indicam o impacto sem autocitações. 
O Spell, além de fornecer o valor absoluto das citações, gera várias medidas de impacto, entre elas, as citações por documento num intervalo de 2 e 5 anos (ver mais sobre impacto por citações em Rossoni, 2019). Nosso Impacto de 2018 foi de 0,333. Isso significa que os artigos publicados pela RECADM nos dois anos anteriores, 2017 e 2016, receberam, em média, 0,333 citações por documento em 2018. No Impacto de 5 anos de 2018, que conta as citações dos artigos publicados entre 2017 e 2013, o impacto foi um pouco maior, 0,369. Quando descontada as autocitações (valores entre parênteses na Tabela 3) - as citações oriundas de artigos da própria RECADM, o impacto para cinco anos é de 0,357 e para dois anos é de 0,292 . Apesar do impacto de 2 anos sem autocitações ser um pouco menor do que o indicador que considera as autocitações, ele é relevante porque é utilizado pela área para ranquear os periódicos. Destaca-se que tal indicador levou a RECADM a ser o $23^{\circ}$ periódico com maior impacto de 2 anos sem autocitações em 2018, entre os 114 periódicos presentes na base.

Para nós, além de uma boa surpresa, ter a RECADM entre os periódicos de maior impacto, cujo número é maior do que vários outros periódicos tradicionais da área, tem um significado especial. Isso porque, entre 2015 e 2017, a revista passou por vários problemas operacionais, que prejudicou a pontualidade das publicações. Com a incorporação da RECADM pelo IBEPES em 2017, as mudanças tecnológicas implementadas e mais capacidade discricionária do corpo editorial para tomar decisões em prol de fomentar a revista nacionalmente, acreditávamos que os resultados só começariam a ser colhidos em 2021. Mas não. No primeiro ano de operação efetiva da nova estrutura da RECADM, conseguimos nos lançar como um dos principais periódicos da área. Para os próximos anos, nossa expectativa é que esses indicadores melhorem ainda mais.

Para finalizar os indicadores de citação da RECADM, gostaria de destacar o índice $\mathrm{H}$ : número de artigos $(\mathrm{N})$ que foram citados $\mathrm{H}$ vezes, em que $\mathrm{H} \geq \mathrm{N}$. $\mathrm{O}$ índice $\mathrm{H}$ demonstra a capacidade de um pesquisador ou de um periódico produzir vários artigos que tenham chances de serem citados de forma mais pulverizada, que somente a contagem de citações. Assim, para se ter um $\mathrm{H}$ alto, não basta ter somente muitas citações, mas ter uma quantidade razoável de artigos citados com um número mínimo de citações. Por isso, essa é uma medida usada muito frequentemente para ranquear pesquisadores e periódicos.

No nosso caso, no Spell, a RECADM tem um índice H de 6, que significa que temos 6 artigos que foram citados, cada um, seis ou mais vezes. Já no Google nosso Hé 19, que significa que temos 19 trabalhos que foram citados 19 ou mais vezes cada um. O Google ainda gera uma estatística chamada H5, que nada mais é que o $\mathrm{H}$ levando em consideração somente as citações recebidas nos últimos 5 anos. Nosso H5 é 14, mostrando que boa parte do nosso H é formado por citações recentes. Do Google também extraímos a medida i10, que mostra quantos artigos foram citados pelo menos 10 vezes. A RECADM possui 52 artigos citados 10 ou mais vezes cada um. Já no Spell, esse índice é menor: 4. 
No entanto, autores não citam revistas, eles citam artigos. Por isso destacamos, na Tabela 4, os artigos mais citados na RECADM, tendo como referência os registros no Spell. Assim como no caso dos artigos mais baixados, os artigos mais citados da RECADM são de áreas e perspectivas teóricas bem variadas. O único destaque evidente é a presença de 3 artigos que versam sobre a sustentabilidade. Além disso, deve-se ressaltar que, até pela questão da longevidade necessária de um artigo para acumular citações, a lista dos mais citados é bem distinta da lista de mais baixados. Eles também apontam para formas de consumo distintas que, por sua vez, possuem usos distintos. Enquanto para o público geral a leitura de artigos científicos serve muito mais para informar, para pesquisadores serve como ponto de partida de uma nova pesquisa. E esse último tipo de consumo só se torna evidente para o público quando um artigo é citado, daí a importância do registro das citações como forma de reconhecer o mérito dos pesquisadores.

Tabela 4. Artigos mais citados da RECADM no Spell.

\begin{tabular}{clc}
\hline Ordem & \multicolumn{1}{c}{ Artigo } & Citações \\
\hline 1 & $\begin{array}{l}\text { A evidenciação dos ativos intangíveis nas empresas brasileiras: empresas que apresentaram informações } \\
\text { financeiras à Bolsa de Valores de São Paulo e Nova York em 2006 e 2007 }\end{array}$ & 13 \\
2 & $\begin{array}{l}\text { Consumo Sustentável: A articulação de um constructo sob a perspectiva do desenvolvimento sustentável } \\
\text { 3 }\end{array}$ & $\begin{array}{l}\text { Prática estratégica e strategizing: mapeamento dos delineamentos metodológicos empregados em estratégia } \\
\text { como prática }\end{array}$ \\
4 & Responsabilidade social corporativa: uma contribuição das empresas para o desenvolvimento sustentável & 11 \\
5 & A universidade do século XXI rumo ao desenvolvimento sustentável & 10 \\
6 & Finanças Comportamentais: análise do perfil comportamental do investidor e do propenso investidor & 8 \\
7 & Mensuração da cultura organizacional: uma análise quantitativa-comparativa & 7 \\
8 & Mudança estratégica, esquemas interpretativos e contexto institucional: um estudo de caso longitudinal & 6 \\
9 & O papel do governo e a prática do consumo sustentável: como esse stakeholder atua no setor elétrico? & 6 \\
\hline
\end{tabular}

Fonte: http://www.spell.org.br/periodicos/ver/58/revista-eletronica-de-ciencia-administrativa, coletado em 13 de dezembro de 2019.

Para fechar nosso balanço, queria destacar que esses números, nem de longe, capturam aquilo que é essencial no trabalho da RECADM. A Revista é feita de empenho, dedicação, muita seriedade e uma demasiada paixão pela academia e pela ciência, cujos valores remetem ao conhecimento gratuito, sem fronteiras e libertador. Algo que é muito difícil de expressar em números, mas que, tacitamente, leitores, autores, corpo editorial e pessoal técnico reconhecem, dando nexo a tudo aquilo que fazemos.

\section{Nesta Edição}

Os artigos desta edição versam primordialmente sobre dois campos distintos. Um sobre estudos organizacionais, cujos artigos tocam na questão do trabalho, seja para explorar suas patologias e a discriminação que existe na atividade feminina nas organizações, seja para explorar como o trabalho criativo pode ser desenvolvido pensando-o estrategicamente. Já o outro campo remete ao comportamento do consumidor, levantando categorias e 
condições sociais, bem como ética e valores pessoais para compreendê-lo, algo que não é tão comum nos estudos da área. Todavia, apesar de áreas tão distintas, coincidentemente, todos os artigos desta edição, de alguma forma, apontam para a identidade e para o processo de identificação como elemento central de explicação dos fenômenos organizacionais, do trabalho e do comportamento do consumidor.

Não é de agora que a identidade nas organizações, na sociedade e de atores do mercado vem ganhando destaque na área de administração. Porém, é curioso verificar que boa parte dos estudos tendem a ignorar que todo o nexo da ação dos indivíduos e, até das organizações, emerge de como atores sociais se identificam com a realidade e com os pares. Mais ainda, é constantemente ignorado na análise organizacional a impossibilidade de se dissociar o significado da realização de atividades estratégias, operacionais e de consumo com a própria figura do indivíduo. Afinal, indo ao encontro do sentido aristotélico de substância, o trabalho, o organizar e o consumir, enquanto atividade humana, por mais instrumental e racional que seja, é indissociável de quem o sujeito é. Afinal, não somente somos o que fazemos, mas também fazemos o que somos.

Assim, o primeiro artigo desta edição é um bom exemplo de como a identidade afeta a relação das pessoas com o seu trabalho. Em "A Estratégia Como Prática em Diferentes Ritmos: um Estudo do Strategizing em Bandas Musicais", Marlos Vinícius Oliveira Ramos e Jacquelaine Florindo Borges propõem um diálogo entre a estratégia como prática social e os estudos culturais, especificamente a articulação entre estilos e identidades a partir da questão: como práticas de estilo moldam o strategizing de bandas musicais? Por meio de um estudo comparativo de onze bandas musicais, os autores identificaram que as bandas desenvolvem quatro práticas estratégicas centrais que emergem de uma construção identitária: identidade sonora; identidade estética; coletivo de identidades e habilidades dos músicos; e identidade econômica. Os autores advogam que a abordagem cultural do strategizing é adequada para compreender organizações cuja produção é essencialmente simbólica, bem como para aquelas que se pautam em processos não rotineiros e criativos de produção. Esse é o caso da produção musical, em que práticas culturais de estilo e interações entre identidades individuais e coletivas são estrategicamente utilizadas.

No segundo artigo, intitulado "Representatividade das Mulheres na Hierarquia de Empresas: Estudo de Caso Com Base no Women's Empowerment Principles", Vera Regina Meinhard e José Henrique de Faria analisam como as práticas preconizadas pelos Women's Empowerment Principles (WMP), inseridas no discurso do desenvolvimento sustentável, promovem ou não a representatividade das mulheres no mundo corporativo. Para tanto, os autores investigaram uma grande indústria metalúrgica com mais de 5.000 funcionários que buscou adotar tais princípios. Segundo os autores, apesar de a empresa estudada se apoiar em um projeto que busca maior representatividade das mulheres, os resultados sugerem que há discrepância entre o discurso e prática. Como bem apontam os autores, todo o processo de implementação das práticas do WMP tem como referência 
atributos masculinos, cabendo às mulheres somente o enquadramento a tais atributos. Além disso, é ignorada, na política da empresa, a hierarquização das relações entre trabalhadoras e trabalhadores. Com efeito, os autores concluem que não existe uma preocupação em superar o modelo de pensamento baseado nas relações hierárquicas de gênero.

O terceiro artigo desta edição, das autoras Carolina Coletta e Heliani Berlato, cujo título é "As Vivências do Trabalho e Suas Suscetibilidades: a patologia como um fim", busca compreender se o trabalho realizado por professoras da educação especial com deficientes intelectuais pode estar associado à síndrome de Burnout. Isso porque as autoras partem do pressuposto que esses profissionais estão mais suscetíveis a sofrerem exaustão emocional, despersonalização e menor realização pessoal dimensões da síndrome - devido ao envolvimento intenso com os deficientes intelectuais. Por meio de um estudo de campo em uma unidade da Associação de Pais e Amigos dos Excepcionais (APAE), as autoras relataram a presença de exaustão emocional por parte das professoras, o que exige maior auxílio da equipe de trabalho. Como consequência, destaca-se que o adoecimento estrutural dos professores na instituição pode gerar condições para a síndrome de Burnout, mesmo não havendo despersonalização nem menor nível de realização pessoal com as atividades.

Os demais artigos, mesmo que indiretamente, remetem à questão da identidade, no entanto focam a figura do consumidor. Assim, no quarto artigo, "Identificar-se com os outros Consumidores Minimiza o Efeito Crowding? O papel da similaridade percebida", os autores Edvan Cruz Aguiar e Salomão Alencar de Farias propõem que a identificação do consumidor com os outros clientes que compartilham o mesmo ambiente de loja minimiza o efeito crowding. Por meio de um estudo experimental, os autores evidenciaram que a similaridade percebida, ou seja, a identificação com os demais consumidores, reduz o efeito negativo do crowding (densidade humana objetivamente na analisada) na percepção de densidade. Em outras palavras, o incômodo com a presença física de outros consumidores é mitigado quando essas outras pessoas são socialmente mais próximas. Tal estudo destaca a necessidade de se considerar as dimensões sociais do ambiente varejista no comportamento do consumidor, cuja área tende a primar por aspectos cognitivos da decisão em detrimento dos condicionantes relacionais.

O quinto artigo, de autoria de Matheus Lemos de Andrade, Ramon Silva Leite e Simone Teresinha Chaves de Andrada Ibrahim, "Ética, Valores Pessoais e a Compra de Falsificados", busca compreender e explicar a propensão à compra de produtos falsificados por meio da ética e valores pessoais. A partir de um levantamento realizado com 479 consumidores, os autores evidenciaram que consumidores mais jovens, de menor renda e com menor escolaridade tendem a consumir produtos falsificados. Os autores também apontaram que os consumidores que se identificam mais com uma ética teleológica instrumentalista tendem a consumir em maior grau produtos falsificados que consumidores que se identificam com uma ética deontológica, mais moralista. Em relação aos valores pessoais, aqueles com propensão mais egoísta, marcados pela Estimulação e Hedonismo, tendem 
a comprar produtos falsificados, enquanto aqueles guiados por valores de maior referência à aceitação social, como Autodeterminação e Realização, tendem a evitar o consumo de tais produtos.

Por fim, no sexto e último artigo desta edição, Mauricio do Nascimento Perini, Fernanda Lazzari, Luciene Eberle e Gabriel Sperandio Milan, no artigo intitulado "Análise dos Fatores Que Influenciam a Intenção de Uso do M-Commerce por Americanos da Geração Millennial", analisaram quais fatores afetam a intenção de uso do m-commerce: (mobile commerce), ou seja, compras realizadas por meio dos smartphones, por americanos identificados como da geração millennial (nascidos entre 1980 e 2003). Baseados na Teoria Unificada de Aceitação e Uso de Tecnologia (UTAUT), os resultados reafirmam a relação entre as variáveis Expectativa de Performance e as Condições Facilitadoras e a Intenção de Uso. Além disso, confirmam a relação entre as variáveis Expectativa de Performance e a Expectativa de Esforço e entre a Expectativa de Esforço e as Condições Facilitadoras. Por fim, apontam para um efeito moderador da idade entre a Influência Social e a Intenção de uso do m-commerce.

Neste ano de 2020, teremos algumas novidades editoriais, como a abertura de chamadas especiais de artigos, a presença de artigos com cunho mais provocativo que analítico, bem como alguns ensaios editorais sobre temas inquietantes acerca da atividade editorial. Será um ano guiado pela consolidação da RECADM como uma revista aberta, gratuita, brasileira e genuinamente em português, que respeita a diversidade de temas e de perspectivas teóricas sem abandonar o rigor acadêmico e científico. Diferentemente dos anos anteriores, que foram de muitas mudanças tecnológicas e estruturais, neste ano focaremos em aprimorar o processo editorial, tentando aproximar alguns grandes nomes da nossa comunidade acadêmica dos autores e leitores.

Assim, despeço-me mais uma vez e, como sempre, agradecendo o empenho dos avaliadores, o profissionalismo da equipe de suporte da RECADM e o apoio financeiro do Instituto Brasileiro de Estudos e Pesquisas Sociais que, apesar de todos os percalços econômicos e desafiadores do fomento à pesquisa no país, mantem a revista viva. Sendo assim, temos esperança de que 2020 seja muito melhor do que o ano que passou, mesmo sabendo do risco de que nada esteja tão ruim que não possa piorar.

Um excelente 2020 e uma prazerosa leitura,

\section{Luciano Rossoni}

Editor da RECADM

\section{Referências}

Rossoni, L. (2019). Impacto por Citações. Zenodo. http://doi.org/10.5281/zenodo.3459906 